\title{
Rubén Darío e Italia
}

\section{LAS Beylezas de Italia desLumran a Darío}

Tuda la obra poética de Dario, y gran parte de su prosa, está llena 1 de la presencia de una Italia ideal, símbolo de la belleza, la gloria y el genio. Italia comparte con Francia el puesto más importante en el corazón del poeta, pero sin las tentaciones exóticas que la segunda de estas naciones implica. Si la belleza de Grecia tiene que ser filtrada a través de Francia para que Rubén Darío pueda sentirla viva dentro de sí, la belleza de Italia no necesita intermediarios.

Cuando Dario realiza, en Igoo, su anhelado viaje a Italia, las primeras páginas de su diario revelan eficazmente la hondura de la presencia de este país en su formación cultural y en su espíritu. Para Darío Italia es algo idealizado y maravilloso, parte importantísima de su mundo interior. Y lo expresa en páginas significativas:

Estoy en Italia, y mis labios murmuran una oración semejante en fervor a la que formulara la mente serena y libre del armonioso Renán ante la Acrópolis. Una oración semejante en fervor. Pues Italia ha sido para mi espítitu una innata adoración; así, en su mismo nombre hay tanto de luz y de melodía, que, eufónica y platónicamente, paréceme que si la lira no se llamase lira, podría llamarse Italia. Bien se reconoce aquí la antigua huella lacónica. Bien vinieron siempre aquí los peregrinos de la belleza de los cuatro puntos cardinales. Aquí encuentran la dulce paz espiritual que trae consigo el contacto de las cosas consagradas por la divinidad del entendimiento, la visión de suaves paisajes, de incomparables firmamentos, de mágicas auroras y ponientes prestigiosos, en que se revela una amorosa y rica naturaleza; la hospitalidad de una raza vivaz, de gentes que aman los cartos y las danzas que heredaron de seres primitivos y poéticos que comunicaban con los númenes; y la contemplación de mármoles divinos de hermosura, de bronces orgullosos de eternidad, de cuadros, de obras en que la perfección ha acariciado el esfuerzo humano, conservadoras de figuras legendarias, de signos de grandeza, de simulacros que traen al artista desterrado en el hoy fragancias pretéritas, memorias de ayer, alfas que inician 
el alfabeto misterioso en que se pierden las omegas del porvenir. Bendita es para el poeta esta fecunda y fecundadora tierra en que Titizo hizo danzar sus cabras. Aquí vuelan aún, ¡oh, Petrarca!, las palomas de tus sonetos. Aquí, Horacio antiguo y dilecto, has dejado tu viña plantada; aquí, celebrantes egregios del amor latino, nacen aún, como antaño, vuestras rosas, y se repiten vuestros juegos y vuestros besos; aquí, Lamartine, rien y lloran de Graziellas, aquí Byron, Shelley, Keats, los laureles hablan de vosotros; aquí viejo Ruskin, están encendidas las siete lámparas, y aquí, enorme Dante, tu figura sombria, colosal, imperiosa, de oculta fuerza demiúrgica, sobresale, se alza ya, dominando la selva sonora, los seres y las cosas con la majestad de un inmenso pino entre cuyas ramas se oye la palabra oracular de un Dios. 1

Es una de las páginas más delirantes de entusiasmo que Dario ha escrito, confesión agradecida de todo lo que él siente deberle al mundo cultural italiano. La presencia de Italia entra en Darío en una extraordinaria vastedad de matices, en su belleza natural y en su cultura, representa la savia del pasado y la vida del presente. El jardín de la belleza, el azul, el sol, repiten en Darío la atracción que el mundo italiano ejerció sobre tantos artistas de todos los tiempos, pero en el poeta de Nicaragua despierta un entusiasmo nuevo, total, porque ahonda sus raíces en el mundo clásico y mitológico que Darío amaba y que para él constituía su evasión necesaria: en este mundo Italia tenía un lugar muy suyo. En su visión del país mediterráneo Rubén Darío lo considera heredero de un pasado fabuloso de cultura, cuya consecuencia aún se repite en el florecimiento singular de las artes, especialmente de la pintura que el poeta aprecia intensamente, en los primitivos, en el Beato Angélico, en Leonardo y el Ticiano, expresiones concretas de un mundo quintaesenciado de gracia, que es el mundo ideal y necesario al poeta.

La "Gioconda", Leonardo, están aludidos infinitas veces en la obra dariana, antes y después de la "Salutación a Leonardo" de los Cantos de vida y esperanza (I905); en el mismo libro el poema "Visión" nos ofrece un recuerdo extraordinariamente vivo de Piranesi; Ticiano aparece con su "panal de rosas y claveles" en la "Balada en honor de las musas de carne y hueso" del Canto errantig (I907); en el poema "Retorno", de Poema del otoño y otros poemas (r9ro) la vuelta de Darío a la patria implica un parangón con Roma, además de serlo con Atenas y Jerusalén.

La belleza de Italia va cantada por el poeta nicaragüense en "La canción de los pinos" del Canto errante, en un derroche singular de colores, en un paisaje de eterna primavera:

1 R. Dario, Diario de Italid, en Obras completas, Madrid, Aguado, 1950, III, pp. 505-506. 
¡oh pinos solares, oh pinos de Italia,

bañados de gracia, de gloria, de azul!

¡oh pinos de Nápoles, rodeados de flores,

oh pinos divinos, no os puedo olvidar!

En su Diario de Italia Rubén Dario expresa todo su entusiasmo frente a la belleza natural de Nápoles, ciudad que "está por Zeus contra el Cristo". ${ }^{2} \mathrm{Y}$ de cuyo espíritu pagano se declara hechizado, porque le hace revivir un pasado glorioso del que ya estaba hondamente prendado. Darío se pregunta sorprendido si está o no en la era cristiana, y se responde:

Se necesitaría embridar la imaginación aventurera con dura brida para creetlo. La mañana arde mansamente en un impecable azul. He subido a las alturas que coronan el puente de San Telmo, punto clásico pata las perspectivas, a fin de ver y vencer antes de abismarme en ese mundo ruidoso que gira y ríe a mis pies. $Y$ en verdad os digo que estamos bajo el imperio de los Augustos. Nada recuerda aquí el madero del Nazareno, nada su religión de angustia; este sol, que en pleno otoño tuesta las rosas de Postum, las cuales dos veces florecen en el año, es el mismo sol jovia! que doraba la frente de Séneca. La bahía de Nápoles, suavemente encorvada y palpitante, como una seda azul sobre un inmenso regazo, canta aún el cum placidum ventis staret mare, en su perpetuo idilio con los islotes de Sirenusa, coros de las rubias ccéanides. El azul del cielo, el histórico azul de ese cielo inmortal, se burla con su flamante brillo de los veinte siglos que han pasado desde que en la dulzura piadosa del Pausílipo se acostaba para dormir su sueño eterno el dulce mantuano gorjeador de églogas. A su derecha la isla de Capri da a las ondas reflejos de aventurina estriada de oro vivo y se aduerme en la misma ociosidad que le valió el mote de Augusto. ${ }^{3}$

Habtá que esperar a Neruda, en los tiempos actuales, para encontrar a otro cantor hispanoamericano tan profundo de la belleza del paisaje italiano. Pero todo el Diario de Rubén Darío es una antología de trozos líricos dedicados al paisaje de Italia y a sus ciudades, a la interpretación de su arte, sobre todo para expresar un gozo de vivir frente a la naturaleza, que de improviso ve corresponder, y hasta superar en belleza lo que había soñado. Hay que leer las páginas dedicadas a Florencia, interpretada en todo su significado de cultura, para entender el entusiasmo del poeta; y la exaltación del paisaje romano, particularmente significativa hoy para nosotros, cuando todo este mundo ha cambiado:

2 Ibid., p. 603.

3 Ibid., pp. 600-601. 
$\dot{Y}$ fue luego un amanecer en las cercanías de Roma, cerca de los lugares encantados que dieron a Possin sus magníficos paisajes. El Tíber iba despacioso entre colinas y frescas campiñas. Apenas comenzaba la luz a insinuarse en el lado oriental, el horizonte se teñía de un dulce violeta, y a trechos un baño de perla suavizaba una tenue irrupción de oro. $Y$ colinas y campiñas se iban poco a poco iluminando en un aumento progresivo de resplandor. Salía de la tierra como un vaho de vida. No era el envenenado respirar de los pantanos pontinos, sino un aliento sano y vivificante. Al vuelo sutil de una brisa impregnada del perfume del campo, temblaban los céspedes ambarinos y las hojas de las anémonas silvestres, y una fina flor áurea que enciende su estrella de fuego a la orrilla del río. $Y$ en una barca, al amor de la corriente, seguimos, con un amigo soñador, un rumbo sobre las aguas en que se desleían los tintes del cielo. Un solitatio pescador arreglaba una red. De los caseríos cercanos llegaba el agudo canto del gallo. $Y$ de pronto fue una fiesta solar el firmamento romano.

El sol había roto las brumas matinales, y surgía, en su imperial pompa, entre peñascos candentes, bajo bóvedas de rubíes vivos. El agua se tiñó de sangre y se encendió de la oriental llamarada. La naturaleza parecía iniciar un canto sin palabras, o con palabras íntimas que iban al espíritu sin formularse en la armonía de las cosas, en la comunión de las ideas humanas con las ideas eternas que emergen en enjambre misterioso de la misteriosa mente del mundo.4

Darío se manifiesta cabalmente en estos pasajes líricos, en los que el paisaje se anima $y$ vive una vida intensa cargada de misterioso embrujo. La palabra expresa, como pocas veces suele darse, lo inefable, el latido del hombre con el ritmo del mundo. Son ejemplos éstos, de los mejores en la literatura de lengua española, y en ellos hay una adhesión total del poeta a la naturaleza, adhesión que, a pesar de todo, no volverá a repetirse en la experiencia italiana de Darío, ni siquiera frente al encanto de Venecia. La ciudad de la laguna representa una esencia que el poeta no llega a hacer suya, a pesar de percibir su belleza, que expresa en pasajes de palpitante lirismo, como el siguiente:

Va la negra góndola. Sale el Gran Canal. La tarde es literaria. El sol va adorablemente dorando con oro violeta las aguas, y con oro rojo pálido la cúpula de San Giorgio... La luz, el paisaje, la armonía suprema natural, el horizonte bistórico, el aire melificado por siglos de besos de amor, los poetas que aquí pasaron, los duxes, los conquistadores... iQué hermoso escenario para veinte años virgenes en una lira! Yo tengo casi el doble, y sin palma; y el instrumento apolíneo creo que se me quedó en Buenos Aires. 5

4 Ibid., pp. 592-593.

5 R. Darío, Tiemas solares, en O.C., cit., III, p. 966. 
Resulta evidente, del pasaje citado, la dificultad, diría física, con que Rubén Darío se acerca a Venecia, ciudad que él no siente vivir dentro de sí, porque se ha transformado en un tópico literario y sobre todo porque a él, hombre al fin y al cabo sencillo, hombre del campo, le falta precisamente la nota familiar que brota de la tierra. Esta desconfianza hacia Venecia no disminuye, sin embargo, el entusiasmo del poeta por las tierras de Italia. Al contrario, llega hasta la formulación de una singular "Italoterapia", con la que concluye Tierra solares:

El mejor sistema de curación para la fatiga de las inmensas capitales, para el hastío del tumulto, para la pereza cerebral, para la desolante neurastenia que os hace ver tan sólo el lado débil y oscuto de vuestra vida: este sol, estas gentes, estos recuerdos, esta poesía, estas piedras viejas. ${ }^{6}$

El amor y el entusiasmo de Darío hacia Italia se manifiestan en una amplia serie de elementos. En la "Oda a Mitre" del Canto errante el poeta celebra con el general argentino al "León italiano", "amigo de América, que amó en fraterno amor", Garibaldi. En el Canto a la Argentina (r9I4) un largo pasaje está dedicado a celebrar la contribución de la sangre italiana al desarrollo y al progreso de esta nación, gente humilde que procede de un país prestigioso, de "Italia, sacra a las gentes".

\section{Los POETAS ITALIANOS Y DARÍo}

En cuanto a la presencia de la literatura italiana en el espíritu de Rubén Darío el autor que más resonancia tiene en él es Dante, seguido por Petrarca, Ariosto, Tasso; entre los más antiguos Cavalca, y de los más modernos y contemporáneos suyos Carducci y D'Annunzio.

Dante, Petrarca, Fra Domenico Cavalca fueron para el poeta un descubrimiento de frescura esencial, así como lo fueron, por influjo de los prerrafaelitas, los grandes pintores, como el Beato Angélico, Botticelli, Leonardo y Ticiano.

La lectura de las Vite scelte dei Santi Padri de Cavalca arranca a Darío expresiones de intenso entusiasmo. En Los raros dedica varias páginas a Fra Domenico Cavalca expresando su admiración ante el clima de mística poesía que se desprende del libro. En la obra en prosa y en verso del fraile, Darío encuentra la misma atmósfera de la pintura de Botticelli: "brilla la luz sencilla y adorable, la exposición milagrosa de

6 Ibid., p. 978. 
las pinturas de un Botticelli". ${ }^{7}$ Lo que más entusiasma al poeta es el candor, la serenidad de una palabra que entra hondamente en el espíritu del lector. El ensayo sobre Cavalca concluye con estas palabras:

Al acabar de leer la obra de Fra Domenico Cavalca siéntese la impresión de una blanda brisa llena de aromas paradisíacos y refrescantes. Hay algo de infantil que deleita y pone en los labios a veces una suave sonrisa. ${ }^{B}$

Este mismo entusiasmo lo manifiesta Darío también en su poesía, en "El reino interior", de Prosas profanas. En 1897 el poeta aludía al "vergel primitivo y paradisiaco de Cavalca", a los "jardines de Jacobo de Vorágine", al "huerto de Croiset", donde "encuentran las almas que las buscan, flores muy peregrinas y exquisitas". En "El reino interior" revive este encanto peregrino que experimentó Darío al leer el libro de Cavalca:

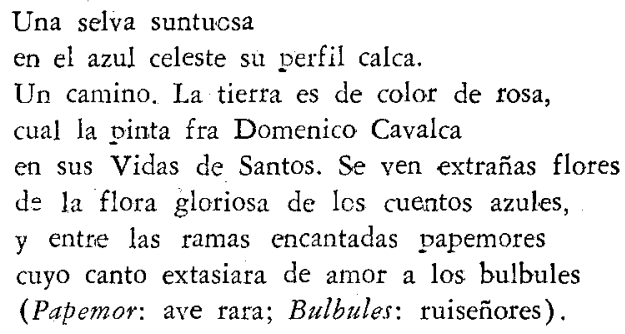

En cuanto a Petratca, son numerosas las huellas que ha dejado en la poesía de Dario. El soneto "Voi ch'ascoltate in rime sparse il suono..." se refleja, presumiblemente, en el famoso "Nocturno" que empieza con el conocido verso: "Los que auscultasteis el corazón de la noche". Exactamente Arturo Marasso habla de una experiencia dolorosa que une al poeta de Nicaragua con el Petrarca del soneto citado, y al mismo tiempo al Dante. ' Más concreta es la proximidad espiritual entre Darío y el Petrarca de I trionfi, en la concepción de la muerte como algo bello; contacto que también lo acerca a Leopardi cuando afirma que Amor y Muerte son las cosas mejores con que cuenta el mundo.

Conocedor profundo del Renacimiento italiano, enamorado de su pintura, Darío es lector asiduo de Ariosto, de Bernardo y Torcuato Tasso.

7 R. Dario, Los raros, en O.C., cit. II, p. 402.

8 Ibid., p. 412.

9 A. Marasso, Rubén Dario y su creación poética, Buenos Aires, Kapeluz, 1954, pp. 24-25. 
Del primero apreciaba la deslumbrante fantasía, la gracia refinada, y de él sacó particulares medios técnicos, como la enumeración colorista de las flores celestes, empleada en "Revelación", cuya fuente ha indicado Marasso en las estrofas 49 y 50 del Canto Xxxiv del Orlando $F_{\mathcal{U}}$ rioso, 10

Muy exactamente el mismo crítico habla de un Darío virgiliano y cervantista, pero de un cervantista que ha leído a Ariosto: "En el paisaje lírico de Rubén hay un parque cervantino. De un Rubén que ha leído y sonreído a Ariosto y que estuvo en los jardines de Armida". ${ }^{11}$ La fábula del poeta italiano aflora en más de un poema de Darío. En la "Sonatina" el "caballo con alas" es el Hipogrifo de Ruggero, el "cavallo alato" del segundo canto, estrofa 48 del Orlando Furioso; en el mismo poema revive todo el resplandor de adorno del Furioso, visible también en el castillo resplandeciente en que la princesa está custodiada por un dragón. La "bestia de Orlando" aparece aludida en la "Balada en honor de las musas de carne y hueso", y es el medio para alcanzar un mundo maravilloso, representado concretamente por los "perfumes de Armida", alusión a los jardines estupendos que Torcuato Tasso canta en la Gerusalemme liberata:

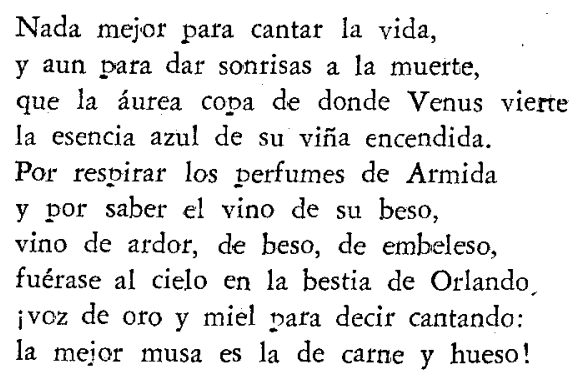

Hemos dicho que es Dante entre todos los poetas italianos el que más hondamente repercute en Darío. Ya en "El porvenir", de Epistolas $y$ poemas (1885), Dante aparece entre Cristo, Job, Juan, Homero y Esquilo, en una "procesión del espíritu gigante"; en el mismo libro vuelve a aparecer Dante entre los grandes, encabezados por Jesús, en el poema "Víctor Hugo a la tumba"; en Los raros Dante recibe, en el capítulo dedicado a Fra Domenico Cavalca, el calificativo de "inmenso", y además Dante es una de las fuentes de los Cantos de vida y esperanza (I905),

\footnotetext{
10 Ibid., p. 297.

11 Ibid., p. 23.
} 
junto con la Biblia, Cervantes, Shakespeare, Platón y Plotino. En las mismas Prosas profanas el "Coloquio de los Centauros" revela una concepción del infierno que procede de Dante a través de Virgilio. Pero especialmente en el poema "Charitas", de los Cantos, cuando Darío describe el viaje del alma de San Vicente del Paul a través de un paraíso que en todo corresponde al de Dante, visto a través de las espléndidas realizaciones gráficas de Doré, como ya ha indicado Marasso. ${ }^{12}$

Además, Darío hace frecuentes alusiones a Dante, directa o indirectamente, como en la mención de las "lóbregas visiones", de los "colores dantescos", en el poema dedicado a Goya. Dante está mencionado directamente en la "Salutación al Aguila" del Canto errante, cual previsor, antes de Colón, de la existencia de un nuevo mundo, el mundo americano. En el poema "Visión", de la misma colección, se habla de un "reino de la lira de Dante" y de Beatriz "paloma que revuela en la luz". Además Darío atribuye a Dante su conversión: ". . . por el amor humano / he llegado al divino. ¡Gloria al Dante!”; y Beatriz aparece ya como símbolo de la pureza: "Beatriz, paloma de los cielos".

En la "Oda a Mitre" la presencia divina de la poesía va representada por Horacio y Virgilio, "guía excelso y amado del Dante". El mismo Mitre adquiere más alta estatura, para Darío, porque tradujo no sólo a Horacio, sino a la Divina Commedia:

En el dintel de Horacio y en la dantesca sombra te vieron las atentas generaciones, alto, fiel al divino origen del Dios que no se nombra, desentrañado en oro y esculpiendo en basalto.

Y para mí, Maestro, tu vasta gloria es ésa: amar los hechos fugaces de la hora, sobre la ciencia a ciegas, sobre la historia espesa, la eterna Poesía, más clara que la aurora. Mitre:

En la misma oda, Darío acerca, en ideal unión, a Garibaldi y a A ambos cubrió la gran sombra del Dante, $y$ en el Dante se amaron...

Nuevamente vuelve la mención de Beatriz y de Dante en la "Balada en honor de las musas de carne y hueso", lo mismo que el poema "Retorno", mientras que en "Santa Elena de Montenegro", al evocar la deso-

12 Ibid., p. 239. 
lación de la tierra asolada por el terremoto, vuelve la mención del conde Ugolino.

Entre los poetas modernos, Carducci está presente en Rubén Darío especialmente por el exámetro, en Cantos de vida y esperanza, en particular con la "Oda a Mitre", la que, según nota Marasso, recuerda los dísticos modernos de Carducci; ${ }^{13}$ mientras el recuerdo temático de "Il bove", de las Rime Nuove, se manifiesta en "Cleopompo y Heliodemo" de los Cantos, a pesar de que en el poema de Darío se trata más bien de "una vaca... crepuscular". Evidentemente el poema tiene mayor parentesco con "Damoetas et Methymne" de Samain, que Rubén Darío transfigura al expresar una problemática personal. Por otra parte el tema tenía amplia difusión, y el mismo Darío había aludido, en $A z u l$, a los ojos del buey "melancólicos y pensativos donde ruedan miradas y ternuras de éxtasis supremos y desconocidos". ${ }^{\text {It }}$ Lo cual no impide que el poeta tuviera presente también al italiano Carducci.

Más que de Carducci, sin embargo, Rubén Darío siente la sugestión de Gabriele D'Annunzio, cuyo valor reconoce, sin aceptar al hombre pasivamente, antes criticándolo muy acertadamente y con extrema serenidad.

En la Autobiografía Darío condena abiertamente la "pose" del poeta italiano15 a quien ha visto en Livorno y en Roma, como se colige del Diario de Italia, donde breves pasajes confirman la poca admiración del poeta de Nicaragua para el hombre "Ni muy joven, ni muy viejo, el aire de un Alcibiades clubman seguro de su efecto..." 16, "un original y un hombre demasiado esquivo y lleno de sí mismo."1z Le molesta sobre todo a Darío, hombre sencillo, al fin y al cabo, y sinceramente ajeno a formas de egolatría, "el ansia de épater" del poeta italiano, a la que atribuye también el fracaso del Martirio de San Sebastian, representado en París ${ }^{18}$ con todos los elementos que habrían podido asegurarle éxito extraordinario: un empresario "lleno de audacia y de dinero", "un gran poeta" como D'Annunzio, una danzarina "famosa y singular" como Ida Rubinstein, un decorador moscovita excepcional y un músico como Debussy. Según Dario, el fracaso del drama se debe sustancialmente a que "se vió el exceso de réclame, la insoportable pose del Imaginífico", su malenten-

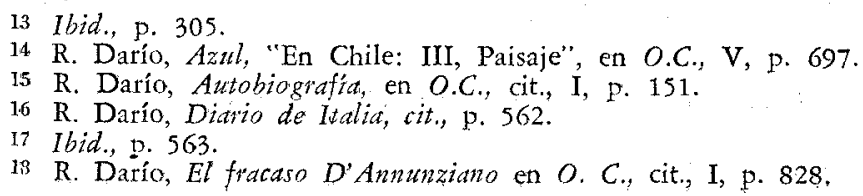


dido empleo de un francés arcaico "en versos fabricados con las repeticiones y maneras usuales al autor en su lengua original". 19

Significativo es el juicio global de Darío sobre D'Annunzio a este propósito: " ¡Lástima de gran poeta, de gran artista verbal, cuyo talento enorme no le ha salvado nunca, ni le salvará de las consecuencias del exhibicionismo y de las charlatanerías, caras a la patria de Barnum?".20

Desde 1896 , Darío había expresado, por otra parte, su admiración hacia el poeta italiano y su obra. En "Garçonnière" afirmaba que

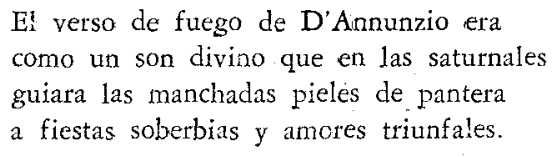

Escribe Max Henríquez Ureña que la influencia de D'Annunzio, "apenas esbozada en algunos rasgos dispersos de Prosas profanas, cobra sobre Rubén Darío mayor fuerza andando el tiempo, después de publicado su Laus vitae (I903), y se manifiesta claramente, por lo menos en cuanto a la forma, en el Canto a la Argentina (I9Io)". ${ }^{21}$ No cabe duda, por lo que se refiere a Prosas profanas, de que el clima general nos lleva a D'Annunzio, por toda una serie de elementos que Darío ha asimilado profundamente, hasta hacerlos materia propia original. Escribe Murga en un ensayo sobre Gabriele D'Annunzio y el mundo de expresión española, que es evidentemente danunciana, en las Prosas, la exaltación pánica de la vida, el preciosismo alexandrino de determinadas estrofas, y sobre todo, haciendo propias las palabras en torno a D'Annunzio de un conocido historiador de la literatura italiana, Ftancesco Flora, "esa participación al sabor de la palabra y a su olor y tacto y sonido como si fuera persona viva (digamos libremente mujer viva), tan presente siempre en el tono danunciano". 22

A D'Annunzio hace remontar Murga la melancolía musical del poeta nicaragüense, la "mitología menor de ninfas, sátiros y faunos y cisnes voluptuosos", 23 añadiendo, sin embargo, que como les pasaba a casi todos los poetas españoles, "la espléndida civilización greco-latina no la

19 Ibid., pp. 825 y 826 .

20 Ibid., p. 826.

21 M. Henríquez Ureña, Breve bistoria del modemismo, México, Fondo de Cultura Económica, 1954, p. 98.

22 F. F. Murga, "Gabriele D'Annunzio e il mondo di lingua spagnola", en G. D'Annunzio nel primo centenario della nascita, Roma, Centro di Vita Italiana, 1963 , pp. 145-146.

23 Ibid., p. 146. 
sentia Rubén con ese fervor de heredero directo como la sentía D'Annuncio. En Rubén Darío se trataba sólo de un motivo de cultura, no de vida más o menos sinceramente anhelada. La maravillosa mitología que esa civilización había inventado y exaltado no podía ser, y no era, para Rubén, más que un elemento de belleza altamente decorativo, al cual no renunció ni siquiera cuando, en los sucesivos Cantos de vida y esperanza, su poesía empezó a hacerse más pensativa y profunda". ${ }^{24}$

Esta afirmación no nos encuentra, naturalmente, conformes: no me parece, en efecto, que Darío viviera con menor fervor que D'Annunzio el mundo de la civilización greco-latina. Por otro lado ir buscando puntos más detallados de contacto entre ambos poetas me parece empresa muy difícil y hasta inútil, en cuanto Rubén Darío era demasiado artista original para ir más allá de una adhesión muy personal al clima danunciano. Su personalidad, la vastedad de sus horizontes poéticos, asimilan y funden en una obra con caracteres indiscutiblemente propios, las impresiones de sus lecturas preferidas, el encanto que sobre él ejerce la poesía escrita por poetas que le eiran afines. Lo demuestra, desde el punto de vista técnico, el uso del exámetro, que si viene de fuera, recibe del genio de Dario esplendor nuevo, luz que se proyecta ampliamente sobre toda la expresión poética castellana. En la historia de sus libros Darío demuestra haber leído a Eugenio Mele, La poesía bárbara en España, ${ }^{25}$ y se sentía continuador legítimo de una tradición ilustre greco-latina, a la que la poesía hispanoamericana daba por primera vez su contribución sustancial a través de su verso.

En su fundamental estudio sobre Darío, Arturo Marasso ha encontrado escasos puntos materiales de contacto con D'Annunzio. Parece singular, sin embargo, que la presencia del poeta italiano se haga más viva a medida que el acento del poeta nicaragüense se vuelve más americano. Me refirio al Canto a la Argentina que Darío escribió con ocasión del primer centenario de la independencia de dicho país. Modelo de la oda, que venía a añaditse con gran dignidad artística en la poesía hispanoamericana, a las de Bello, de Olmedo y de Andrade, es el libro de las Laudi de D'Annunzio. Del poeta italiano Darío aprende el procedimiento que da amplitud al himno, transporte lírico singular al poema, y acude con preferencia al novenario, interrumpiéndolo con octosílabos y decasílabos, después de haber comenzado con el verso libre.

A través de las páginas del Däario de Italia, parece evidente que las

24 Tbid., pp. $146-147$.

25 R Dario, "Historia de mis libros", en $O$. C., cit., I, p. 216. (El libro de E. Mele se editó en Bari, 1910). 
lecturas de la obra de D'Annunzio se han ensanchado y se extienden a varias de las novelas más famosas, Il fuoco, L'innocente, Il trionfo della morte, Le vergini delle rocce, Il piacere... que, como indica Murga, ${ }^{26}$ se estaban entonces difundiendo en traducciones españolas. Lo documenta la serie de menciones del poeta italiano en las páginas del Diario, y el recuerdo de los jardines encantados descritos por él tantas veces: en Génova, por ejemplo, el jardín de Palacio Rosozza le recuerda a Darío los jardines danuncianos; "lugar deseable para la realización de una vida de amor", es un jardín "bellísimo lleno de verdura y de flores, en donde los chorros de agua dicen rimas de D'Annunzio". ${ }^{27}$

En Tierras solares Rubén Darío encuentra una singular identidad entre la vieja ciudad misteriosa, Venecia, y D'Annunzio:

...Piedras de Venecia, ¿quién diría vuestros encantos, vuestros mirterins, vuestros maravillosos secretos, vuestras floraciones de idea y de arte? Muchos lo han dicho, y el mejor, y el último, ese inexcusable D'Annunzio... Y he aqui que D'Annunzio se me asemeja a esa prodigiosa Venecia... ¿Raro? No sé:28

A pesar de admirar tanto al poeta italiano, Darío conserva intacta su independencia de juicio frente a él, como ya hemos subrayado en las opiniones sobre el carácter del hombre, distinguiendo siempre entre el gran artista que consideraba igual a un $\operatorname{dios}^{29}$ y el hombre vano y orgulloso. Es la misma independencia que el poeta de Nicaragua conserva frente a otro italiano, Marinetti, y al futurismo, movimiento que sostiene ya fundado por el mallorquino Gabriel Alomar. ${ }^{30}$ Según Darío, Marinetti es "un poeta italiano de lengua francesa", pero un "buen poeta, un notable poeta". ${ }^{31}$ En cuanto a su poesía Dario escribe: "Los poemas de Marinetti son violentos, sonoros, y desbridados. He ahí el efecto de la

26 F. F. Murga, at. cit., pp. 147-148.

27 R. Darío, Diario de Italia, cit., p. 524

28 R. Dario, Tierras solares, cit., p. 965.

29 R. Darío, "Marinetti y el futurismo", en O. C., cit., I, p. 623. Es significativo el pasaje en que el "dios" es reducido por Darío a proporción decididamente humana, pues lo llama "El calvo D'Annunzio", lo ve cargado de años, "no sé cuántos tiene ya"; más adelante dice el poeta: "Los dioses se van y hacen bien. Si así no fuese no habría cabida para todos en este pobte mundo. Ya se irá también D'Annunzio. $Y$ vendrán otros dioses que asimismo tendrán que irse cuando les toque el turno, y asi hasta que el cataclismo final haga pedazos la bola en que rodamos todos hacia la eternidad, y con ella todas las ilusiones, todas las esperanzas, todos los impetus y todos los sueños del pasajero rey de la creación".

30 Ibid., p. 617.

31 Ibid, p. 616. 
fuga italiana en un órgano francés. $\mathrm{Y}$ es curioso observar que aquel que más se le parece es el flamenco Verhaeren". 32

La vitalidad del movimiento futurista impresiona indudablemente a Darío, y en él ve la vitalidad propia de la juventud. "La principal idea de Marinetti - escribe-33 es que todo está en lo que viene y casi nada en lo pasado". Lo futuro es para Darío "el incesante turno de la Vida y de la Muerte. Es lo pasado al revés". De modo que "Hay que aprovechar las energías en el instante, unidos como estamos en el proceso de la universal existencia. $\mathrm{Y}^{\Upsilon}$ después dormiremos tranquilos $\mathrm{y}$ por siempre jamás. Amén".34

El que juzga al futurismo italiano es un Darío de más de cuarenta años, un hombre experimentado, que ya sabe el valor de la vida y que ve el fenómeno poético desde dentro, es decir con participación viva en la euforia vital de los jóvenes.

\section{Resonancias y VALioración de Darío en Italia}

Como hemos visto, Italia, su paisaje, su pintura, sus poetas, tienen un lugar único en el gran poeta de Hispanoamérica. Es interesante ver ahora qué resonancia ha tenido Darío en Italia a través del tiempo. Pobre poeta de un país desconocido a la mayoría de los europeos, no mereció por cierto la atención del Dios amado, D'Annunzio, a quien ni siquiera se atrevió a entrevistar, como sabemos en el Diario de Italia. ${ }^{35} \mathrm{Y}$ en Italia Rubén Darío es todavía poco menos que un desconocido; su obra no ha logrado, siquiera en estos últimos años, cuando se mira a la literatura hispanoamericana con seria atención, despertar todo el interés que seguramente merece. A parte la selección dedicada a la poesía dariana por Oreste Macrí en su antología de la poesía española del novecientos, en I952,36 y por Francesco Tentori en otra antología de I957, dedicada a la poesía hispanoamericana del mismo periodo, ${ }^{37}$ incluyendo otras selecciones menores en antologías poéticas más generales, como Orfeo: il tesoro della lirica universale, recopilado por Vincenzo Errante y Emilio Mariano, ${ }^{38}$, la Antologia della poesia straniera cuidada por Attilio Bertoluc-

32 Ibid, p. 617.

33 Ibid., p. 623.

34 Ibidem.

35 R. Darío, Diario de Italia, cit., pp. 562-563.

36 O. Macrí, Poesia spagnola del Novecento, Parma, Guanda, 1952.

37 F. Tentori, Poesiat ispano-americana del'900, Parma, Guanda, 1957.

38 Orfeo: il tesoro della livica universale, a cura di V. Errante e E. Mariano, Firenze, Sansoni, 1950 (2a ed., 1962, en dos tomos). 
ci, ${ }^{39}$ los Poeti del novecento italiani e stranieri, recopilados por Elena Croce, ${ }^{40}$ y L'Italia dei poeti, al cuidado de Emilio Mariano, ${ }^{41}$ sólo dos antologías han aparecido dedicadas expresamente a la poesía de Rubén Darío, ambas en r96r, debida la una a G. Regini, Poesía, 42 la otra a Vincenzo de Tomasso, Poema dell'Autunno e altre poesie.43

Por lo que atañe al juicio crítico, no existiendo antes en Italia un verdadero hispanoamericanismo, no sorprende que en el Repertorio bibliográfico recopilado por Giovanni Maria Bertini en I94I, los años I890I940,44 se encuentre una única ficha dedicada al poeta, la de un estudio de F. Gobotto, titulado "Il mimo di Nicaragua: Rubén Darío", aparecido en la Gazzeltita Litteraria nada menos que en I 89. 45 Una verdadera atención crítica hacia la obra de Rubén Darío, se inicia en Italia con los hispanistas que aparecen después de la Segunda Guerra Mundial, profesores universitarios, que extienden sus investigaciones no sólo al ámbito español, sino al mundo de la creación artística americana. En 19.49 Franco Meregalli dedica varias páginas críticas al estudio del poeta de Nicaragua en un libro sobre el Modernismo, Glí iniziatori' del Modernismo,46 y en un estudio introductivo a una edición de las poesías de José Asunción Silva. 47

La posición de Meregalli frente a Darío es interesante: el crítico italiano estudiando al poeta, en Gli iniziatori del Modernismo, se sitúa en posición crítica, buscando en él los latidos propios del hombre $y$ demostrando su íntima adhesión a la posición de Unamuno, conquistado sólo más tarde por la bondad del poeta nicaragüense y por la producción última y más seria de su poesía.

En la parte primera de su ensayo Meregalli pregunta: ¿cómo es posible que después de tantos reparos, como expresaron Vargas Vila, Rufino Blanco Fombona, Unamuno, que nunca se sintieron cerca de Darío, llegaran a considerarlo y declararlo grandísimo poeta, después 1958.

39 Antologia della poesia straniera, a cura di A. Bertolucci, Milano, Garzanti,

40 E. Croce, Poeti del Novecento italiani e stranievi, Torino, Einaudi, 1960.

41 L'Italia dei poeti, a cura di E. Mariano, Milano, Nuova Accademia, 1961.

42 R. Dario, Poesia, a cura di G. Regini, Introduzione di G. Bellini, Milano, Nuova Accademia, 1961.

43 R. Dario, Poema dell'Autunno e altre poesie, a cura di V. De Tomasso, Milano, Ceschina, 1961.

4 G. M. Bertini, "Contributo a un repertorio bibliografico italiano di letteratura spagnola (1890-1940)", en Italia e Spagna, Firenze, Le Monnier, 1941.

45 F. Gabotto, "Il mimo di Nicaragua: Rubèn Darío", Gazzetta Létteraria, Toris, $1891, \mathrm{XV}$. 1949

46 F. Meregalli, Gli "Iniziatori" del Modernismo, Milano, La Goliardica,

47 J. A. Silva, Poesías, a cura di F. Meregalli, Milano, Cisalpino, 1949. 
de haberle considerado "menos de un hombre normal", y cuando nunca expresaron amor para su poesía? La respuesta que da el crítico es que todos lo hicieron "movidos, además que por una extrínseca admiración para sus capacidades técnicas, por una no menos extrínseca simpatía por su bondad de hombre". 48

Meregalli dedica luego su atención a las primeras obras de Darío, anteriores a $A z u l$, y pone de relieve la "bipolaridad" de sus aspiraciones literarias, entre Homero y Teócrito, dualismo que no sabrá resolver nunca, ni después de Prosas profanas ${ }^{49}$ Este "equívoco" lo encuentra el crítico también en $A z u l$, libro al que niega auténtica poesía, "esto es una manera verdaderamente nueva y sugestiva de ver las cosas, una representación de la realidad que tenga inmanente en sí una interpretación de ella. No hay en $A z u l$ la imagen creadora, sintética; es, el de $A z u l$; un tipo de literatura más cuidado que el de la producción anterior, pero, en la mayoría de los casos, no es más genial". ${ }^{50}$

En cuanto a Prosas profanas Meregalli afirma que es el más francés de todos los libros de Darío.51 En este libro el exotismo del poeta se transforma en "deseo de totalidad, asume un aspecto pánico que atenúa a nuestros ojos la impresión de limitación ideal que solamente deja en Darío". ${ }^{52}$ A pesar de su reconocido valor, el libro no obtiene la adhesión del crítico italiano, el cual hasta en el clasicismo del poeta encuentra una postura esnobista, y afirma que el clasicismo de Darío es ante todo ritmo, estilización. ${ }^{53}$ El crítico pone de relieve que el Darío de Prosas profanas resulta totalmente ajeno al sentimiento del pasar del tiempo y la ineluctabilidad de la muerte.54 Meregalli va buscando en el poeta esa seriedad, que llega sólo cuando Darío envejece y tiene su mayor documento en los Cantos de vida y espieranza, donde se manifiesta la nostalgia del tiempo "en que se vivia y no se pensaba". A este propósito resulta interesante el acercamiento que el crítico hace entre Dario y Carducci: para él Darío es como Carducci, "uno de esos hombres que sienten el pensamiento como una polilla, como algo a que pueden ser obligados, pero que no entra en sus inclinaciones instintivas". ${ }^{55}$ Lo que para Meregalli salva a Darío de la superficialidad en ese tono humano,

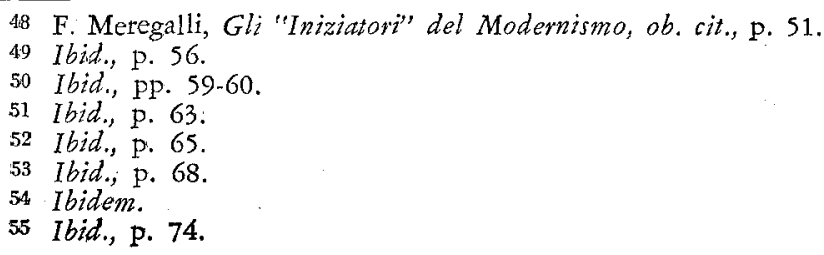


que le aproxima a Manuel Gutiérrez Nájera y a José Asunción Silva.56 El crítico llega a la conclusión de que si Darío es un gran poeta, lo es en esta segunda etapa; a pesar de lo cual la verdadera importancia histórica de su obra está en Prosas profanas, algo que remedan los máximos representantes de la poesía castellana que vinieron después, asimilando sus novedades y superándolas.

La categoría historicoliteraria "Modernismo" tiene su texto en Prosas profanas, afirma Meregalli, y no incluye ni la emoción romanticoindividualista de Silva, ni la panteísta y civil de los Cantos de vida y esperanza.

En el estudio introductivo a las poesías de Silva vuelve Meregalli a tratar de Darío y su obra poética, situando en una posición casi antitética al gran poeta colombiano. En Silva el crítico encuentra ya una hostilidad reticente hacia el Modernismo, ${ }^{57}$ y pone de relieve la mayor estimación que del poeta hacía Unamuno, sucesivamente conquistado por la humanidad del nicaragüense. ${ }^{5}$ Según Meregalli, Silva y Darío son personalidades totalmente diversas; el parangón entre los dos sirve para poner de relieve más las diferencias que la continuidad, y hay que estudiar a Silva por sí, no en función de un poeta tan diferente como Darío. ${ }^{5}$ Esta diferencia sustancial entre la seriedad de la problemática de Silva y la superficialidad de Darío, antes de los Cantos die vida y esperanza, va subrayada constantemente por el crítico. Los juicios confirman siempre la desconfianza con que Meregalli se acerca a Darío.

A pesar de sus reparos, los estudios de Franco Meregalli extienden en Italia el conocimiento del poeta nicaragüense. En I952 Oreste Macrí, en la ya citada antología de la poesía española del novecientos, vuelve a tratar de Darío, insistiendo sobre la identidad entre Modernismo y Noventayocho. Es Macrí el crítico que más ha apreciado, en Italia, el significado estético de la obra dariana, sin dejar a un lado, por supuesto, su significado ético, la amargura lucreciana ya denunciada por Juan Valera. Escribe Macrí que "Una zona particular del estetismo puro de Darío debió de impresionar a los jóvenes del '98: su extrema estilización hermética", y añade: "Es el Darío del porvenir, fúlgidamente salido de las trabas del decadentismo, como el mejor D'Annunzio de Alcyone, concreto en la elección simbolista de la idea-verbo".60

En su introducción al Modernismo literario iberoamericano, Erminio

56 Ibid., p. 75

57 F. Meregalli, "Introduzione" a J. A. Silva, Poesias, ob. cit., p. 5.

58 Ibid., pp. 6-7.

59 Ibid., p. 8.

60 O. Macri, Poesía spagnola del Novecento, ob. cit., $2^{a}$ ed., Parma, Guanda, 1961, p. XXVI. 
Polidori trata también a Darío, dando valoración positiva de su obra poética, que considera "pura, elevada, armónica", una poesía que tiene su razón de ser en sí misma y en la sensibilidad del poeta, un fondo patético nuevo y sobre todo estilo y forma nuevos.61 Según Polidori, el poeta Darío lleva a sus consecuencias extremas su revolución, consciente de ser el reformador de la poesia española y de que le toca a él darle a América una literatura propia. El crítico pone de relieve en Azul que el paisaje americano forma el fondo del arte dariano; 62 en Prosas profanas ve el triunfo de la naturaleza, la carne, la belleza, el lujo oriental;63 en Cantos de vida y esperanza encuentra que Darío pasa desde los ímpetus juveniles a la reflexión de la edad madura, desde la belleza femenina a la del creador, rayo de Dios. ${ }^{4}$ Polidori acentúa el significado religioso de la poesía dariana, subrayando el paso del "verso azul y la canción profana" al "hambre de espacio y sed de cielo"; una especie de arrepentimiento, una imploración de perdón a Dios y a los hombres por haberse alejado demasiado de los unos y del otro. ${ }^{65}$

Los demás libros del poeta son, para el crítico, inferiores a los Cantos de vida y esperanza; el "misticismo" dariano coexiste con el panteísmo y es un "misticismo de reacción" en el cual inesperadamente se sienten vibraciones pasionales.66 En cuanto al concepto de patria en Darío, Polidori afirma la completa adhesión del poeta a los destinos de su raza, y la conclusión es que el "genio errante" vagó por la poesía, "sediento de verdad y de ideal. Pero, alimentado en las tierras del paganismo y de la fuente del pesimismo, milagrosamente se transformó y transfundió, sobre su tierra y su familia española, para dar cantos de fe patriótica y religiosa e himnos de optimismo. La polifonía gozosa de la 'Salutación del optimista' es el himno de la hispanidad o, si se prefiere, de la latinidad". ${ }^{67}$

En un estudio sobre el modernismo en la poesía castellana, publicado en I955, Cesco Vian, tratando de Dario rápidamente, más interesado en desentrañar el significado del Modernismo en la poesía hispánica, reconoce al poeta el mérito máximo, no de haberle dado la independencia intelectual a la América de idioma castellano, ni de haber introducido en la poesía hispánica nuevas formas, nuevos ritmos, nuevos vocablos

61 E. Polidori, Introduzione allo studio del Modernismo letterario iberoamericano, Milano, Gastaldi, 1953, p. 126.

${ }_{62}$ Ibid., p. 129.

63 Ibid., p. 135.

ou Ibid., p. 142.

65 Ibidem.

65 Ibid., p. 148.

67 Ibid., pp. 155-156. 
expresivos, sino el mucho mayor de haber unificado a todos los poetas del mundo hispánico, borrando toda diferencia entre civilizadores y civilizados e instaurando, con palabras de Juan Ramón Jiménez, "el reino del espíritu y de la idea" en la poesía española contemporánea.68

A continuación, en un medallón crítico dedicado expresamente a Darío, Vian declara su inconformidad hacia el hombre moralmente débil, poeta apresurado y aproximado, de cultura superficial, como resulta de muchos poemas; ${ }^{69}$ sin embargo pone el acento sobre la definición de Antonio Machado, para quien Darío es el "ruiseñor de los mares", el Darío "marino" de Jiménez en Españoles de tres mundos, el "idolo, evocador de misterios... con la tristeza vasta y enorme esculpida en los ídolos aztecas", como lo definió Valle-Inclán. ${ }^{70}$ Los reparos de Unamuno, quien reprocha al poeta la falta de toda cultura "que no sea exclusivamente literaria", le parecen, al contrario, al crítico italiano, un gran elogio, en cuanto para él la poesía verdadera es sólo un tartamudeo, una tentativa para expresar lo inexpresable, visto y entendido en sueños e imposible de expresar plenamente al despertar. De ahí el juicio que, "precisamente en la vaga melodía di ondulanti reminiscenze está lo mejor de la poesía dariana". 71

Vian considera a Darío un poeta por naturaleza, que tuvo el don del canto y su canto se volvió música; en su existencia "de mestizo errabundo, desarraigado, sensual y triste, siempre vuelto a la búsqueda de sensaciones nuevas y más fuertes, siempre combatido entre la carnie que tienta con sus frescos racimos y la tumba que aguarda con sus fuinebres ramos, dio a su canto los elementos más sinceros de inspiración. Cuando su discurso no lo sostiene el interés autobiográfico, decae en el discurso de nadie". ${ }^{72}$ En fin, Vian ve en Darío al lírico que "supo llegar a una desnuda y absoluta verdad poética saliendo de la maraña cansada de las largas ejercitaciones y las nieblas de los confusos símbolos". ${ }^{73}$

En el mismo año I955 aparece un extenso estudio de Vittorio Borghini sobre Rubén Dario e il Modernismo: se trata de una exaltación de la obra del poeta; y el crítico lamenta, en la conclusión, que el siglo veinte haya exterminado el buen gusto y pocos respeten hoy el arte. Según Borghini la poesía dariana es "arte y naturaleza, tradición e in-

68 C. Vian, Il "Modernismo" nzella poesia ispanica, Milano, La Goliardica, 1955, p. 44.

\footnotetext{
69 Ibid., pp. 155-156.

70 Ibid., pp. 157-158.

71 Ibid., p. 160 .

72 Ibid., pp. 160-161.

73 Ibid., p. 162.
} 
novación, en una rara armonía de sabiduría y espontaneidad", y le reprocha a los "novadores" el frecuente olvido de esta armonía.74

En la poesía de Rubén Dario el crítico encuentra tres temas dominantes: el del hombre "de senso" o "erotismo agónico" hacia la mujer y los placeres de la vida; del hombre de "pensamiento", o sea el acongojado pesimismo frente a los problemas de la vida; del hombre "civil", en los ideales del ciudadano de América, nacido de estirpe latina.75 Se trata, para Borghini, de una humanidad inquieta del poeta, sobre la que descansa una especie de pirámide de tres fachadas, su poesía; un excepcional sentido estético va transfigurando los distintos temas en constante belleza de músicas e imágenes, dando unidad a toda su obra. ${ }^{76}$

A juicio del crítico, la grandeza de Darío no tiene comparación posible en el ámbito de la poesía moderna, y ningún poeta de los que le han seguido, con excepción de Antonio Machado y Juan Ramón Jiménez, puede acercársele. ${ }^{77}$ Borghini expresa, además, en su libro, que su valoración de Dario es una empresa solitaria que va contra la corriente de la crítica moderna.

También en mi estudio sobre La poesía modernista ${ }^{78}$ Rubén Darío tiene, como es normal, parte relevante, y en él subrayo particularmente la importancia de Prosas profanas, a pesar de expresar una neta simpatía por la parte de la obra dariana que más hondamente nos revela al hombre que ha ido adquiriendo conciencia de los problemas eternos de la vida, que ha percibido, en fin, el significado del tiempo, es decir sobre todo los Cantos de vida y esperanza, entendidos como el punto final de su particular modernismo, y al mismo tiempo la conclusión del extraordinario poeta que fue Rubén, el cual, a pesar de muchas flaquezas, ha sabido dar a la expresión castellana ese resorte vital que la condujo a realizar en el novecientos un nuevo "Siglo de Oro". La misma línea interpretativa sigo, sustancialmente, en mi Introduzione alla poesia di Rubén Dario,79 sólo en parte modificada posteriormente, con una mayot atención hacia los Cantos siguientes. ${ }^{80} \mathrm{La}$ poesía dariana atrae y aleja, al mismo tiempo, al crítico que se pone a estudiarla. Pero hay que confesar

74. V. Borghini, Rubén Dario e il Modemismo, Genova, Istituto Univ. di Magistero, 1955, pp. 431-432.

75 Ibid., p. 433.

76 Ibidem.

77 Ibid., p. 434.

78 G. Bellini, La poesia modernista, Milano, Cisalpino, 1961.

79 G. Bellini, "Introduzione alla poesia di Rubén Dario", en R. Darío, Poe. sin, ob. cit.

30 G. Bellini, "Significado y permanencia de la poesía de R. Dario", en "Homeraje a R. Darío", de la revista Atenea, Santiago de Chile, en vía de publicación. 
que en cualquier momento, y a cada nueva lectura, ella resiste y se nos presenta con matices nuevos, que con sorpresa notamos se nos habían escapado anteriormente. Por más que se le ataque, por consiguiente, Datío queda como un gran poeta; por más antipatía que se tenga hacia particulares aspectos de su obra, ésta resiste al tiempo. "Gran toro del alba de nuestra poesía", lo ha definido Miguel Ângel Asturias, "el más travieso de los poetas que parió Dios", ${ }^{81}$ y como tal Rubén Darío resiste a todos los asaltos del tiempo y de los hombres. Cuando, andando los años, volvemos a leer sus versos, la primitiva impresión de superficialidad se esfuma, desaparece, y hasta en lo que nos parecía más empalagoso encontramos la presencia del gran artista y sobre todo del hombre que en todo momento fue Darío, con sus anhelos y sus debilidades, con sus grandezas y sus miserias. Nos explicamos así el por qué un poeta comprometido como Neruda haya podido tributarle entusiasta homenaje y declararlo "poeta grande, desde entonces y para siempre e imprescindible". ${ }^{82}$ El "mensaje ecuménico" que Pablo Antonio Cuadra ha visto venir, "del silencio substancial de los siglos y de las cosas nicaragüenses", a difundirse por el verso de Darío, ${ }^{83}$ sigue vivo y operante. Los años que miden la fama y el valor verdadero de los hombres han destacado aún más el significado permanente del poeta nicaragüense, un clásico de las letras castellanas en las que opera una revolución del valor de las de Garcilaso y de Góngora.

Universidad "Bocconi",

GIUSEPPE BELLINI Milán

81 M. A. Asturias, "Prólogo" a Páginas de Rubén Dario, Buenos Aires, Eudeba, 1963. Cit. Encuentros con Rubén Dario (recopilación y notas de E. Rodríguez Monegal), "Mundo Nuevo", París, 1967, 7, p. 19.

82 P. Neruda, en "Charla F. García-Lorca-P. Neruda sobre R. Darío", en F. Garcia Lorca, Obras completas, Madrid, Aguilar, 1955 ( $2^{8}$ ed. $)$, p. 1633.

83 P. A. Cuadra, "Introducción al pensamiento vivo de Rubén Dario", en Torres de Dios, Managua, Academia Nicaragüense de la Lengua, 1958, p. 124. 